\title{
Calsequestrin 2 (CASQ2) mutations increase expression of calreticulin and ryanodine receptors, causing catecholaminergic polymorphic ventricular tachycardia
}

\author{
Lei Song, ${ }^{1}$ Ronny Alcalai, ${ }^{2}$ Michael Arad,, ${ }^{3}$ Cordula M. Wolf, 4 Okan Toka, ${ }^{2}$ David A. Conner, ${ }^{2}$ \\ Charles I. Berul, ${ }^{4}$ Michael Eldar, ${ }^{3}$ Christine E. Seidman, ${ }^{1}$ and J.G. Seidman ${ }^{2}$

\begin{abstract}
1Department of Genetics, Harvard Medical School, and Howard Hughes Medical Institute, Boston, Massachusetts, USA. ${ }^{2}$ Department of Genetics, Harvard Medical School, Boston, Massachusetts, USA. ${ }^{3} \mathrm{Heart}$ Institute, Sheba Medical Center, and Tel Aviv University, Tel Aviv, Israel. ${ }^{4}$ Department of Cardiology, Children's Hospital Boston, and Department of Pediatrics, Harvard Medical School, Boston, Massachusetts, USA.
\end{abstract}

\begin{abstract}
Catecholamine-induced polymorphic ventricular tachycardia (CPVT) is a familial disorder caused by cardiac ryanodine receptor type 2 (RyR2) or calsequestrin 2 (CASQ2) gene mutations. To define how CASQ2 mutations cause CPVT, we produced and studied mice carrying a human $\mathrm{D} 307 \mathrm{H}$ missense mutation $\left(\mathrm{CASQ}^{307 / 307}\right)$ or a CASQ2-null mutation (CASQ ${ }^{\triangle \mathrm{E} 9 / \triangle \mathrm{E} 9}$ ). Both $C A S Q 2$ mutations caused identical consequences. Young mutant mice had structurally normal hearts but stress-induced ventricular arrhythmias; aging produced cardiac hypertrophy and reduced contractile function. Mutant myocytes had reduced CASQ2 and increased calreticulin and RyR2 (with normal phosphorylated proportions) but unchanged calstabin levels, as well as reduced total sarcoplasmic reticulum (SR) $\mathrm{Ca}^{2+}$, prolonged $\mathrm{Ca}^{2+}$ release, and delayed $\mathrm{Ca}^{2+}$ reuptake. Stress further diminished $\mathrm{Ca}^{2+}$ transients, elevated cytosolic $\mathrm{Ca}^{2+}$, and triggered frequent, spontaneous $\mathrm{SR} \mathrm{Ca}^{2+}$ release. Treatment with $\mathrm{Mg}^{2+}$, a RyR2 inhibitor, normalized myocyte $\mathrm{Ca}^{2+}$ cycling and decreased CPVT in mutant mice, indicating RyR2 dysfunction was critical to mutant CASQ2 pathophysiology. We conclude that CPVT-causing CASQ2 missense mutations function as null alleles. In the absence of CASQ2, calreticulin, a fetal $\mathrm{Ca}^{2+}$-binding protein normally downregulated at birth, remains a prominent SR component. Adaptive changes to CASQ2 deficiency (increased posttranscriptional expression of calreticulin and RyR2) maintained electrical-mechanical coupling, but increased RyR2 leakiness, a paradoxical response further exacerbated by stress. The central role of RyR2 dysfunction in CASQ2 deficiency unifies the pathophysiologic mechanism underlying CPVT due to $R y R 2$ or $C A S Q 2$ mutations and suggests a therapeutic approach for these inherited cardiac arrhythmias.
\end{abstract}

\section{Introduction}

Catecholamine-induced polymorphic ventricular tachycardia (CPVT) is a familial arrhythmogenic disorder characterized by adrenergic-stimulated VT that can deteriorate into ventricular fibrillation to cause sudden cardiac death $(1,2)$. Recurrent syncope, seizures, and cardiovascular collapse are triggered by exercise or emotional stress $(2,3)$. Mutations in the cardiac sarcoplasmic reticulum (SR) $\mathrm{Ca}^{2+}$ release channel, ryanodine receptor type $2(R y R 2)$, or in cardiac calsequestrin 2 (CASQ2), a SR Ca ${ }^{2+}$-storage protein, cause CPVT $(2,4)$. Despite considerable knowledge about the coupling of $\mathrm{Ca}^{2+}$ release from the SR, activation of sarcomere contraction, and $\mathrm{Ca}^{2+}$ reuptake into the SR during relaxation (reviewed in refs. 5, 6), the mechanisms by which CASQ2 mutations alter $\mathrm{Ca}^{2+}$ handling or cause CPVT are incompletely understood.

Nonstandard abbreviations used: AV, atrial-ventricular; CASQ2, calsequestrin 2; CPVT, catecholamine-induced polymorphic ventricular tachycardia; CRT, calreticulin; EP, electrophysiological; HR, heart rate; LVEDD, LV end diastolic diameter; LVESD, LV end systolic diameter; PLN, phospholamban; RyR2, ryanodine receptor type 2; $\mathrm{SCR}$, spontaneous SR $\mathrm{Ca}^{2+}$ release; SERCA2, sacroplasmic or endoplasmic reticulum $\mathrm{Ca}^{2+}$ ATPase 2; SR, sarcoplasmic reticulum; VPB, ventricular premature beat; VT, ventricular tachycardia.

Conflict of interest: The authors have declared that no conflict of interest exists. Citation for this article: J. Clin. Invest. 117:1814-1823 (2007). doi:10.1172/JCI31080.
CASQ, the most abundant $\mathrm{Ca}^{2+}$-buffering protein in the lumen of striated muscle SR $(7,8)$, is encoded by the skeletal (CASQ1) and cardiac (CASQ2) calsequestrin genes $(9,10)$. Each molecule of CASQ2, a 415-amino acid polypeptide, binds 40-50 $\mathrm{Ca}^{2+}$ with low affinity $\left(K_{\mathrm{d}}=1 \mathrm{mM}\right)$, allowing cardiac SR Ca ${ }^{2+}$ concentrations to approach $20 \mathrm{mM}$ while free $\mathrm{Ca}^{2+}$ concentrations are only $1 \mathrm{mM}$ (7, 11-13). CASQ2 also participates in regulating SR $\mathrm{Ca}^{2+}$ release (14). With junctin and triadin, CASQ2 binds RyR2 to form the SR luminal RyR2 $\mathrm{Ca}^{2+}$ release channel complex $(15,16)$. Some investigators hypothesize that CASQ2 functions as a sensor of SR luminal $\mathrm{Ca}^{2+}$ in the transduction pathway linking RyR2 activity with $\mathrm{Ca}^{2+}$ storage $(7,14-16)$.

Recessive mutations in CASQ2 that encode either truncated or missense polypeptides have been identified in CPVT patients (4, 17-19). Based on their study of CASQ2 truncation mutations, Postma and collaborators suggested that the absence of CASQ2 caused CPVT (4), a model supported by several recent studies. A truncated CASQ2 peptide $(\mathrm{G} 112+5 \mathrm{X})$ expressed in rat ventricular myocytes was incapable of binding $\mathrm{Ca}^{2+}(18)$, and a CASQ2-null mouse (20) caused significant increases in SR volume, with marked reduction in levels of junctin and triadin. CASQ2-null mice also had premature spontaneous $\mathrm{Ca}^{2+}$ release and CPVT arrhythmias.

The mechanism by which CASQ2 missense mutations cause disease is less well understood. The CASQ2 missense mutation 
A

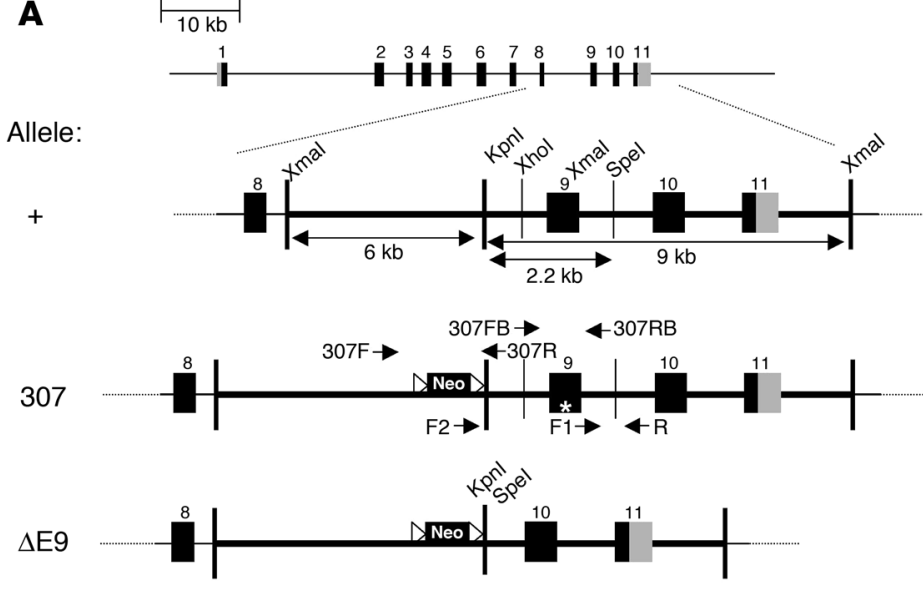

B

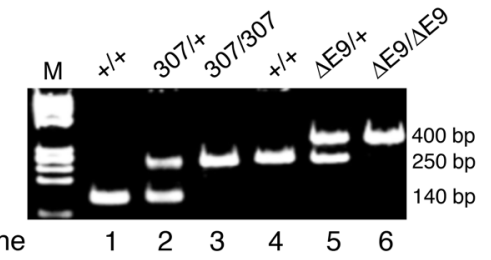

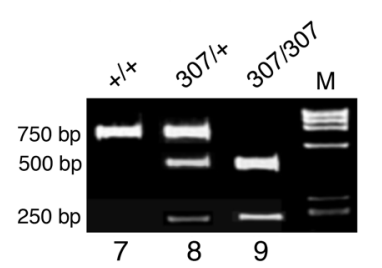

\section{Figure 1}

Introduction of missense mutation $\mathrm{D} 307 \mathrm{H}$ and exon 9 deletion into the mouse CASQ2 gene. (A) The mouse CASQ2 gene is encoded in 11 exons spread over $70 \mathrm{~kb}$. The WT (+), D307H knock-in (307) and exon 9-deletion $\mathrm{KO}(\Delta \mathrm{E} 9)$ alleles are contained on a 15-kb Xmal restriction fragment, which encodes exons 9-11. (B) The genotypes of WT (+/+), D307H-knockin heterozygous (307/+) and homozygous (307/307), and exon 9deletion KO heterozygous $(\Delta \mathrm{E} 9 /+)$ and homozygous $(\Delta \mathrm{E} 9 /$ $\Delta \mathrm{E} 9$ ) mice were determined by size characterization of PCRamplified DNA fragments. The WT and Neo-excised alleles of D307H-knockin mice were amplified using primers 307F and 307R, which yielded 140-bp and 250-bp fragments, respectively (lanes $1-3$ ). The WT and $\Delta \mathrm{E} 9$ alleles were amplified with primers $\mathrm{F} 1, \mathrm{~F} 2$, and $\mathrm{R}$, producing 250-bp and 400-bp fragments, respectively (lanes 4-6). The D307H allele was amplified by PCR primers 307FB and 307RB, which yielded a 750-bp fragment. After BamHI digestion, the $\mathrm{D} 307 \mathrm{H}$ allele produced 500-bp and 250-bp bands (lanes 7-9). M, molecular marker.
D307H, identified in 7 Bedouin CPVT families (17), substitutes a negatively charged Asp residue for a positively charged His residue. The Asp residue is contained within a highly negatively charged CASQ2 domain, which has been highly conserved during vertebrate and invertebrate evolution (17). Overexpression of CASQ2 $\mathrm{D} 307 \mathrm{H}$ protein in adult rat cardiomyocytes decreased $\mathrm{SR} \mathrm{Ca}^{2+}$ content, altered $\mathrm{Ca}^{2+}$ transients, and caused multiple local $\mathrm{Ca}^{2+}$ release events (21) while expression of recombinant human CASQ2 $\mathrm{D} 307 \mathrm{H}$ protein showed reduced binding to triadin and junction (22). Recent studies (18) of rat myocytes that overexpressed the CASQ2 missense protein $\mathrm{L} 167 \mathrm{H}$ indicated that this mutant retained normal biophysical $\mathrm{Ca}^{2+}$-binding properties and concluded that CPVT was caused by disrupted interactions between CASQ2 missense mutants and other SR proteins.

To understand the in vivo pathophysiology of distinct CASQ2 mutations, we constructed and studied 2 lines of mutant mice. The $\mathrm{D} 307 \mathrm{H}$ mutation was engineered into the endogenous mouse CASQ2 gene, and homozygous CASQ ${ }^{307 / 307}$ mice were produced. We also constructed mice in which the endogenous CASQ2 gene lacked exon 9; $\mathrm{CASQ}^{\triangle \mathrm{E} 9 / \triangle \mathrm{E} 9}$ mice are homozygous for this truncation allele. As expected, CASQ2 protein was not detectable in $\mathrm{CASQ}^{\Delta \mathrm{E} 9 / \Delta \mathrm{E} 9}$ mice, but remarkably, $\mathrm{CASQ}^{307 / 307}$ mice also had significantly reduced protein levels. Both mutant mice showed increased RyR2 levels and strikingly increased levels of calreticulin (CRT), another luminal $\mathrm{Ca}^{2+}$-binding protein. While these compensatory changes preserved normal cardiac development and function at rest, significant abnormalities in $\mathrm{Ca}^{2+}$ handling were observed with stress. Both mutant models exhibited arrhythmic phenotypes characteristic of human CPVT and were responsive to therapeutic interventions that targeted RyR2. Based on our study of the electromechanical responses to CASQ2 depletion and the resultant compensatory responses, we propose a novel mechanism by which CASQ2 mutations cause CPVT. RyR2 dysfunction, due in part to replacement of CASQ2 by CRT, is central to this model and implies that a common pathophysiologic mechanism accounts for CPVT from either CASQ2 or RyR2 mutations.

\section{Results}

Heterozygous knockin $\left(\mathrm{CASQ}^{307 /+}\right)$ and heterozygous $\mathrm{KO}\left(\mathrm{CASQ}^{\Delta \mathrm{E} 9 /+}\right)$ mice were constructed using standard homologous recombination techniques (Figure $1 \mathrm{~B}$ and Methods). Homozygous mutant mice $\left(\mathrm{CASQ}^{307 / 307}\right.$ or $\mathrm{CASQ}^{\Delta \mathrm{E} 9 / \Delta \mathrm{E} 9}$ ) were generated by breeding. Development, growth, behavior, and reproductive fitness, were similar in mutant and WT mice (data not shown).

$R N A$ and SR protein analysis in CASQ2-mutant mice. CASQ2 RNA and protein levels were assessed in the hearts of 15- to 20-week-old mice. Both RNA and protein levels in $\mathrm{CASQ}^{307 /+}$ and $\mathrm{CASQ}^{\Delta \mathrm{E9} /+}$ mice approximated levels in WT mice (Figure 2, A and B). Neither CASQ2 RNA nor protein was detected in $\mathrm{CASQ}^{\triangle \mathrm{E} 9 / \triangle \mathrm{E} 9}$ hearts (Figure 2, A and B). CASQ ${ }^{307 / 307}$ mice had normal CASQ2 mRNA levels, but protein levels were dramatically reduced ( $<95 \%$ of normal) (Figure 2, A and B). Based on these data, we concluded that $\mathrm{CASQ}^{\Delta \mathrm{E} 9}$ and $\mathrm{CASQ}^{307}$ encode functionally null alleles and that both homozygous mutant mouse lines are CASQ2 deficient.

We considered whether the absence of CASQ2, the primary $\mathrm{Ca}^{2+}$-binding protein in the heart, triggered compensatory expression of $\mathrm{Ca}^{2+}$-binding proteins CASQ1, CRT, and sarcalumenin. Normally low levels of CASQ1 mRNA were unchanged in mutant hearts (Figure 2A and data not shown). CRT mRNA levels were comparable (Figure 2A), but in contrast, CRT protein levels were dramatically increased in both homozygous CASQ ${ }^{307 / 307}$ and $\mathrm{CASQ}^{\Delta \mathrm{E} 9 / \Delta \mathrm{E} 9}$ hearts (Figure 2, B and C). Levels of sarcalumenin, another $\mathrm{SR} \mathrm{Ca}^{2+}$-binding protein, were similar in WT and CASQ2deficient mice (Figure 2D).

Levels of other $\mathrm{Ca}^{2+}$-regulating proteins, including RyR2, triadin, junctin, sarcoplasmic or endoplasmic reticulum $\mathrm{Ca}^{2+}$ ATPase 2 (SERCA2), $\mathrm{Na}^{+} / \mathrm{Ca}^{2+}$ exchanger, and phospholamban (PLN), were evaluated (Figure 2, D and E, and Supplemental Figure 1A; supplemental material available online with this article; doi:10.1172/ JCI31080DS1). Among these proteins, only RyR2 showed levels (both phosphorylated at residue Ser2809 and nonphosphorylated) that were significantly elevated, approximately 6-fold (Figure 2, F and G) in CASQ2-deficient hearts. Because both phosphorylated 
A
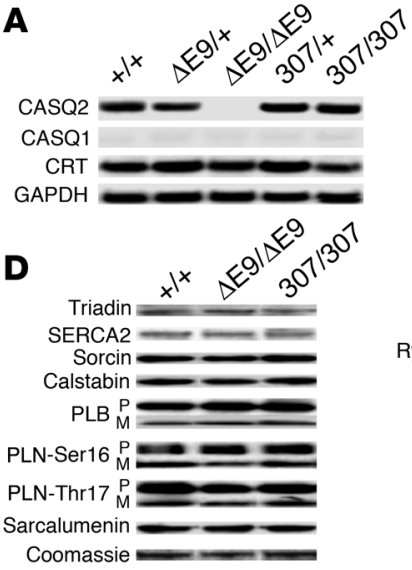

$\mathbf{F}$

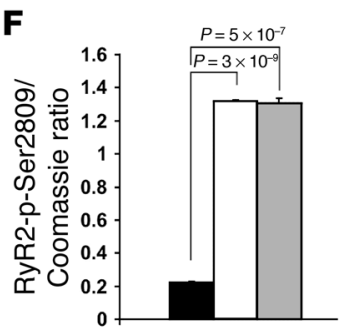

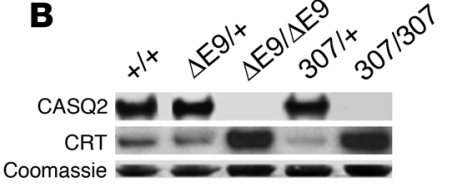

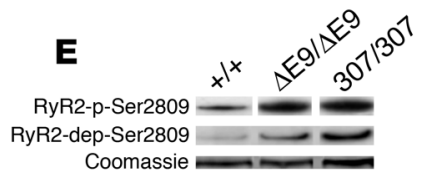

Coomassie
C
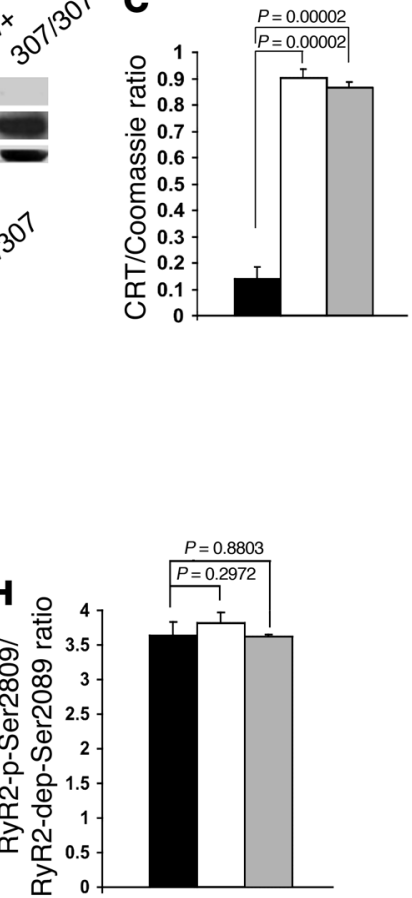

Figure 2

Assessment of RNA and proteins in CASQ2-deficient hearts. (A) Cardiac mRNA levels of CASQ2, CASQ1, and CRT in age-matched $(n=3)$ WT $(+/+)$, heterozygous $\left(\mathrm{CASQ}^{\mathrm{EE9} /++} \mathrm{CASQ}^{307 /+}\right)$, and homozygous (CASQ ${ }^{\Delta E 9 / L E 9}$; CASQ ${ }^{307 / 307)}$ mice. Note low and comparable CASQ1 RNA levels and normal, comparable CASQ2 and CRT RNA levels in WT and CASQ $307 / 307$ mice. In contrast, CASQ2 RNA levels are very low in CASQ ${ }^{\triangle E 9 / 1 E 9}$ mice. GAPDH RNA was used for normalization. (B) Representative Western blots show dramatic reduction in CASQ2 protein expression in hearts from CASQ ${ }^{\Delta E 9 / / E}$ and $\mathrm{CASQ}^{307 / 307}$ mice and increased cardiac CRT protein levels $(n=3)$. (C) Densitometry of Western blots $(n=3)$ shows significantly increased CRT levels in CASQ ${ }^{\triangle E 9 / A E 9}$ (white bar) and CASQ ${ }^{307 / 307}$ (gray bar) versus WT (black bar) hearts. (D) Western blot analyses of triadin, SERCA2, sorcin, calstabin, PLN monomers $(\mathrm{M})$ and pentamers $(\mathrm{P})$, phosphorylated PLN (residues Ser16 and Thr17) monomers and pentamers, and sarcalumenin showed unchanged levels in CASQ2-deficient hearts $(n=3)$. (E) Western blots of both dephosphorylated (RyR2-depSer2809) and phosphorylated (RyR2-p-Ser2809) RyR2 in CASQ2-deficient and WT hearts. (F and G) Densitometry of Western blots ( $n=3$, normalized to Coomassie blue-stained proteins) showed that both phosphorylated and dephosphorylated RyR2 were significantly increased (WT versus $\mathrm{CASQ}^{\Lambda E 9 / / \mathrm{ES}}$ or $\mathrm{CASQ}^{307 / 307}$ ) and ratios $(\mathbf{H})$ of phosphorylated RyR2 (RyR2-p-Ser2809) and nonphosphorylated (RyR2-dep-Ser2809) were unchanged.

and nonphosphorylated RyR2 were proportionately elevated in

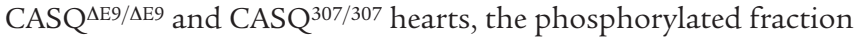
of RyR2 in WT and mutant hearts did not change (Figure 2H). These results differ from recent studies of another CASQ-deficient mouse (20) in which RyR2 levels were reported as unchanged while triadin levels were decreased. Different fractionation protocols, in particular, use of the $\mathrm{Ca}^{2+}$-chelator EDTA (20), which may destabilize the RyR2-triadin CASQ2-deficient complex from microsomal fractions, may account for these differences. RyR2 mRNA levels were similar in mutant and WT hearts (data not shown).

Cardiac hypertrophy in aged $C A S Q^{307 / 307}$ and $C A S Q^{\triangle E 9 \triangle E 9}$ mice. Echocardiographic assessment of cardiac morphology showed no structural or functional differences between mutant and WT mice at 15 weeks of age. However, at 35 weeks of age, both $\mathrm{CASQ}^{\mathrm{AEg} / \Delta \mathrm{E} 9}$ and $\mathrm{CASQ}^{307 / 307}$ mice had LV hypertrophy and reduced ejection fraction compared with WT mice (Table 1). Gross cardiac anatomy revealed significant atrial enlargement in both homozygous

mutant mouse lines (Figure 3A) compared with WT or heterozygous mutant mice. Cardiac histopathology did not identify fibrosis (Figure 3B) or myocyte disarray (data not shown) in hypertrophied mutant hearts.

Stress-induced ventricular arrbythmias in homozygous mutant mice. Comprehensive electrophysiological (EP) studies were performed on homozygous and heterozygous mutant mice and WT controls ( $n \geq 8$ per group, ages $14-20$ weeks). Conscious electrocardiograms showed significantly slower resting heart rates (HRs) $(465 \pm 44 \mathrm{bpm})$ in both $\mathrm{CASQ}^{307 / 307}$ and $\mathrm{CASQ}^{\triangle \mathrm{Eg} / \mathrm{AEg}}$ mice compared with WT or heterozygous mutant mice $(612 \pm 78$ bpm; $P<0.01)$. There were no significant differences in PR, QRS, and QT intervals between mutant and WT mice (PR, $35.1 \pm 1.6$ versus $34.5 \pm 1.6$; QRS, $11.9 \pm 2.2$ versus $12.9 \pm 2.5$; QT, $23.6 \pm 2.7$ versus $25.5 \pm 4.9$; all values in $\mathrm{ms}$ ). During telemetric ECG recordings, unstressed CASQ2-deficient mice had multiple arrhythmias: $80 \%$ had ventricular premature beats (VPBs), including couplets and triplets, $40 \%$ had nonsustained VT, and 1 mouse had several episodes of prolonged sustained VT. Ventricular bigeminy or polymorphic couplets after each sinus beat occurred commonly (Figure 4, A and B). Arrhythmias were more frequent at the beginning of the recording period; we attributed this to mild stress associated with cage transfers for telemetry. These transient arrhythmic events resolved within minutes. No WT or heterozygous $\mathrm{CASQ}^{307 /+}$ or $\mathrm{CASQ}^{\mathrm{EE} / /+}$ mice had any ventricular arrhythmias (Table 2).

Stress was provoked in mice by treadmill exercise or catecholamines, and ECG recordings were obtained. Stress-induced ventricular arrhythmias, such as isolated VPBs, nonsustained VT, and multiple events of sustained VT (Figure 4C), occurred in all CASQ2-deficient mice. Arrhythmias typically began early in exercise or 1 minute after catecholamine injection and lasted up to 20 minutes into recovery. Catecholamines induced more frequent and more severe arrhythmias compared with exercise (Table 2). Of 10 mutant mice, six $\left(3 \mathrm{CASQ}^{307 / 307}\right.$ and $3 \mathrm{CASQ}^{\triangle \mathrm{Eg} / \triangle \mathrm{EE}}$ ) displayed bidirectional VT (Figure 4C), a stereotypical morphology in human CPVT $(1,23)$. Although all VT events were polymorphic, HRs never exceeded 1,000 bpm, and VT rhythms never deteriorated to ventricular fibrillation or caused hemodynamic decompensation. Although exercise or catecholamine injection occasionally induced isolated premature ventricular and supraventricular beats in WT or heterozygous $C A S Q^{307 /+}$ and $\mathrm{CASQ}^{\triangle \mathrm{E} 9 /+}$ mice, none of these mice had significant ventricular arrhythmias (Table 2). Atrial arrhythmias, including atrial premature beats (APBs), short runs of supraventricular tachycardia (SVT) (Figure 4C), and atrial fibrillation 


\section{Table 1}

LV function of WT and CASQ2 mutant mice

\begin{tabular}{|c|c|c|c|c|c|c|}
\hline Age & Parameter & $\mathrm{CASQ}^{+/+}(n=6)$ & $\mathrm{CASQ}^{307 /+}(n=3)$ & $\mathrm{CASQ}^{307 / 307}(n=6)$ & $\operatorname{CASQ}^{\Delta E 9 /+}(n=3)$ & $\mathrm{CASQ}^{\triangle \mathrm{EE} / \triangle \mathrm{EEg}}(n=6)$ \\
\hline \multirow[t]{5}{*}{15 weeks } & LVAW (mm) & $0.86 \pm 0.07$ & $0.90 \pm 0.03$ & $0.92 \pm 0.03$ & $0.90 \pm 0.04$ & $0.89 \pm 0.03$ \\
\hline & LVPW (mm) & $0.85 \pm 0.07$ & $0.90 \pm 0.02$ & $0.90 \pm 0.04$ & $0.89 \pm 0.04$ & $0.89 \pm 0.03$ \\
\hline & LVEDD (mm) & $2.87 \pm 0.15$ & $2.97 \pm 0.15$ & $2.84 \pm 0.19$ & $2.92 \pm 0.04$ & $2.94 \pm 0.25$ \\
\hline & LVESD (mm) & $1.04 \pm 0.14$ & $1.13 \pm 0.10$ & $1.13 \pm 0.14$ & $1.01 \pm 0.09$ & $1.09 \pm 0.08$ \\
\hline & FS & $64.00 \% \pm 4.00 \%$ & $62.00 \% \pm 3.00 \%$ & $60.00 \% \pm 3.03 \%$ & $65.33 \% \pm 3.51 \%$ & $60.33 \% \pm 2.88 \%$ \\
\hline \multirow[t]{5}{*}{35 weeks } & LVAW (mm) & $0.90 \pm 0.03$ & $0.90 \pm 0.07$ & $1.08 \pm 0.05^{A}$ & $0.91 \pm 0.05$ & $1.06 \pm 0.04^{A}$ \\
\hline & LVPW (mm) & $0.89 \pm 0.09$ & $0.90 \pm 0.07$ & $1.07 \pm 0.03^{B}$ & $0.90 \pm 0.04$ & $1.00 \pm 0.04 \mathrm{~B}$ \\
\hline & LVEDD (mm) & $2.91 \pm 0.07$ & $2.85 \pm 0.03$ & $3.18 \pm 0.31$ & $3.03 \pm 0.17$ & $3.01 \pm 0.11$ \\
\hline & LVESD (mm) & $1.07 \pm 0.15$ & $1.14 \pm 0.12$ & $1.34 \pm 0.41$ & $1.26 \pm 0.13$ & $1.26 \pm 0.25$ \\
\hline & FS & $60.33 \% \pm 3.06 \%$ & $59.98 \% \pm 4.51 \%$ & $52.00 \% \pm 1.00 \% \mathrm{~B}$ & $55.02 \% \pm 3.53 \%$ & $53.17 \% \pm 4.31 \%^{\mathrm{B}}$ \\
\hline
\end{tabular}

LVAW, LV anterior wall; LVPW, LV posterior wall; FS, fractional shortening. ${ }^{A} P<0.01 ;{ }^{B} P<0.05$ versus WT.

(not shown), occurred in $80 \%$ of stressed CASQ2-deficient mice but not in stressed WT or heterozygous mutant mice.

Invasive in vivo EP studies of anesthetized mice were performed. No significant difference in atrial-ventricular (AV), atrial-His bundle, or His bundle-ventricular intervals or in the AV refractory periods were found between homozygous mutant and WT mice. No WT or heterozygous $\mathrm{CASQ}^{307 /+}$ or $\mathrm{CASQ}^{\mathrm{LE} 9 /+}$ mice had sinus node dysfunction, atrial arrhythmias, or ventricular arrhythmias during EP studies. In contrast, 4 CASQ2-deficient mice had sinus node dysfunction with recurrent events of severe sinus bradycardia, nodal escape rhythms (Figure 4D), and short runs of atrial fibrillation induced by rapid atrial pacing (data not shown). Ventricular arrhythmias were much less frequent in EP studies than in telemetry studies, perhaps due to anesthesia effects, but mild ventricular arrhythmia occurred in 4 CASQ2-deficient mice: isolated VPBs or short runs of polymorphic VT after rapid RV pacing (not shown).

$\mathrm{Mg}^{2+}$ inhibited stress-induced arrbythmias. Because $\mathrm{Mg}^{2+}$ inhibits RyR2 release of SR $\mathrm{Ca}^{2+}(24)$ and can effectively treat some cases of polymorphic VT (25), we examined whether $\mathrm{Mg}^{2+}$ attenuated stress-induced arrhythmias in mutant mice. Pretreatment of WT and CASQ2-deficient mice with i.p. $\mathrm{Mg}^{2+}$ prior to catecholamine injections did not alter the frequency of mild arrhythmias (Table 2). However, pretreatment with $\mathrm{Mg}^{2+}$ significantly $(P=0.02)$ lowered the incidence of catecholamine-induced sustained VT in CASQ2deficient mice (Table 2).

$S R \mathrm{Ca}^{2+}$ and contractility in isolated CASQ2-deficient myocytes. Isolated myocytes from 15-week-old WT and CASQ2-deficient mice had comparable baseline sarcomere lengths and myocyte contractility (assessed by percentages of sarcomere shortening) (Table 3 and Figure 5A).

Myocytes were loaded with the $\mathrm{Ca}^{2+}$-sensitive fluorescent dye fura-2 to measure SR $\mathrm{Ca}^{2+}$ content. With electrical pacing, diastolic $\mathrm{Ca}^{2+}$ level and total $\mathrm{Ca}^{2+}$ transients were similar in CASQ2-deficient and WT myocytes (Table 3 and Figure 5A), but CASQ2-deficient

\section{Figure 3}

Cardiac morphology and histology of CASQ2-deficient hearts. (A) Gross cardiac anatomy of adult WT $(+/+)$ and $\mathrm{CASQ}^{307 / 307}$ mice $(n=4)$ demonstrated enlarged atria (arrows) and ventricles in mutant hearts. (B) Low magnification of paraffin-embedded ventricular transverse heart sections from 35-week-old mice studied with Masson trichrome stain. No fibrosis was observed in either WT $(+/+)$ or homozygous $\mathrm{CASQ}^{307 / 307}$ mice $(n=4)$. (B). Scale bars, $1 \mathrm{~mm}$. myocytes had significantly prolonged $\mathrm{Ca}^{2+}$ release (time to peak level) and $\mathrm{Ca}^{2+}$ reuptake (time constant for $\mathrm{Ca}^{2+}$ transient decay, $\tau$ ). Total SR $\mathrm{Ca}^{2+}$ content, assessed after a caffeine bolus, was significantly lower in CASQ2-deficient myocytes compared with WT myocytes (Figure 5C). Caffeine depletion of SR $\mathrm{Ca}^{2+}$ normalized differences in the $\mathrm{Ca}^{2+}$ transients between CASQ2-deficient and WT myocytes (Supplemental Figure 1B and Supplemental Table 1 ), indicating that $\mathrm{Ca}^{2+}$ transport across the sarcolemmal membrane, presumably via the L-type $\mathrm{Ca}^{2+}$ channel and the $\mathrm{Na}^{+} / \mathrm{Ca}^{2+}$ exchanger, were unchanged in CASQ2-deficient myocytes.

$\mathrm{Mg}^{2+}$ blocked epinephrine-induced $\mathrm{SR} \mathrm{Ca}^{2+}$ depletion and spontaneous $\mathrm{Ca}^{2+}$ release. $\mathrm{Ca}^{2+}$ response to epinephrine was assessed in isolated myocytes. Catecholamine treatment increased peak $\mathrm{Ca}^{2+}$ levels, decreased $\mathrm{Ca}^{2+}$ transit times, and enhanced contractility in WT myocytes. In contrast, epinephrine significantly elevated diastolic $\mathrm{Ca}^{2+}$ levels and paradoxically decreased total $\mathrm{Ca}^{2+}$ transients in CASQ2-deficient myocytes (Figure 5, A and B, and Table 3).

Epinephrine-treated CASQ2-deficient myocytes showed spontaneous $\mathrm{SR} \mathrm{Ca}{ }^{2+}$ release (SCR) (Figure 5, D and E). The frequency of SCR correlated with increased diastolic $\mathrm{Ca}^{2+}$ levels and decreased
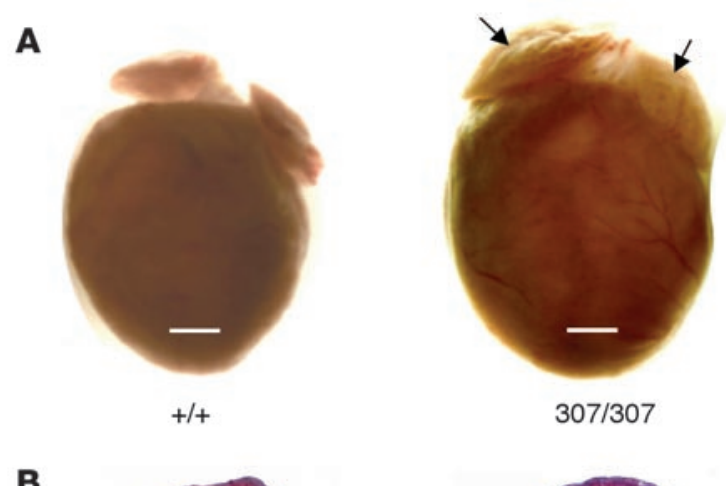

B
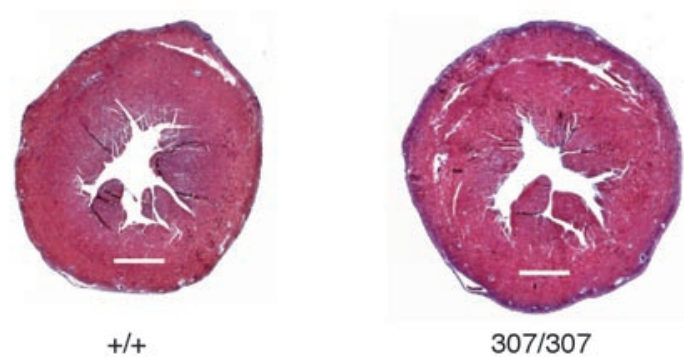

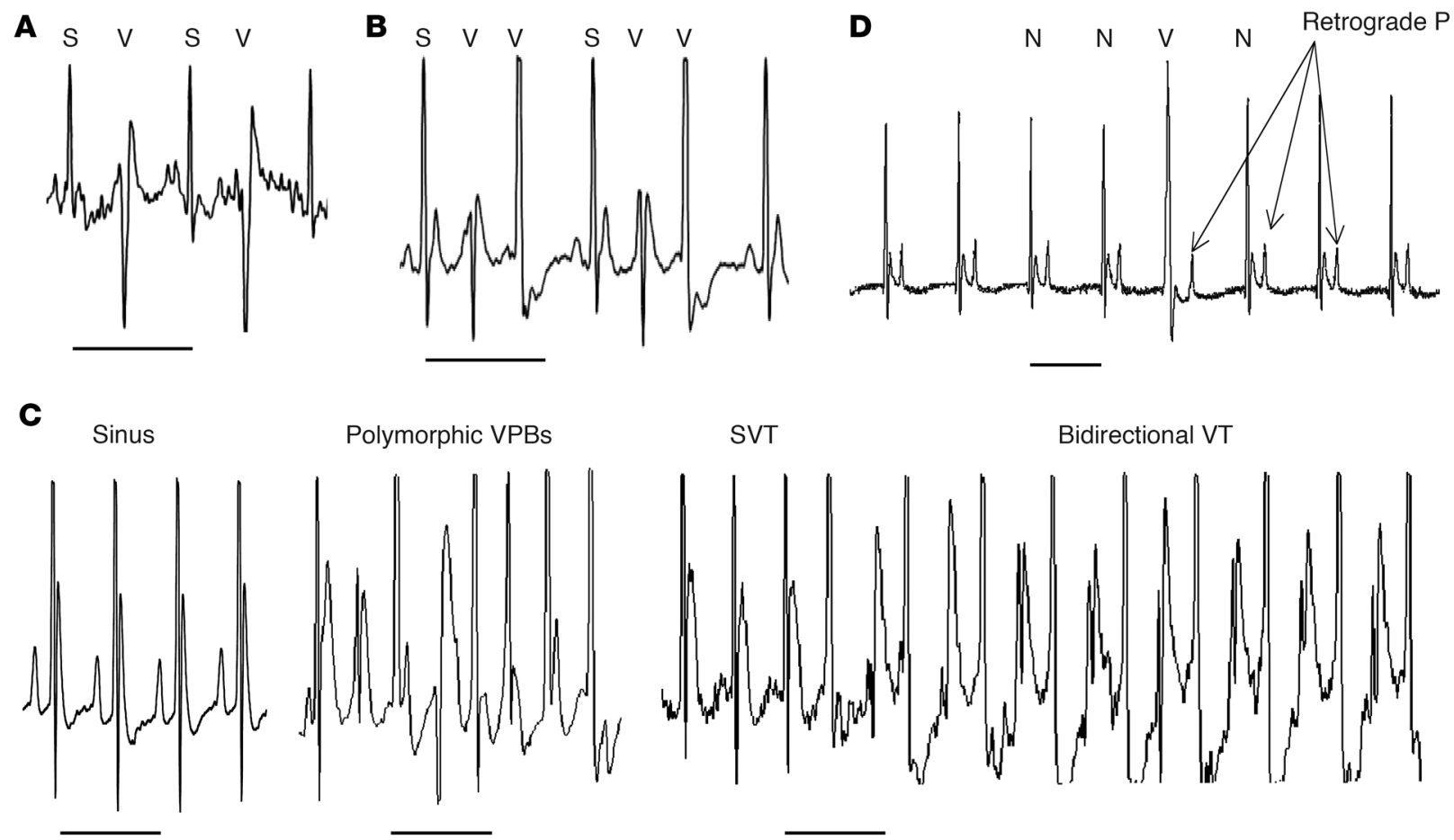

Bidirectional VT

\section{Figure 4}

Representative ventricular arrhythmias recorded in CASQ2-deficient mice. (A) Ventricular bigeminy in a resting CASQ ${ }^{\triangle E 9 / \triangle E 9} \mathrm{mouse}$. (B) Dimorphic ventricular couplets induced by exercise in a CASQ ${ }^{307 / 307}$ mouse. (C) Telemetry recording of CASQ ${ }^{307 / 307}$ mouse showed baseline sinus rhythm (left), but after isoproterenol administration, multiple polymorphic VPBs and supraventricular tachycardia (SVT) occurred, which deteriorated to sustained polymorphic VT with bidirectional pattern. (D) Sinus arrest with nodal escape during EP study in $C A S Q^{\Delta E 9 / \triangle E 9} \mathrm{mouse}^{\mathrm{L}} \mathrm{V}$, ventricular beat; $\mathrm{S}$, sinus beat; $\mathrm{N}$, nodal beat; $\mathrm{P}, \mathrm{p}$ wave. Scale bar: 0.2 second.

peak height of $\mathrm{Ca}^{2+}$ transients in paced myocytes (Figure 5D). Repetitive SCR usually deteriorated to prolonged $\mathrm{Ca}^{2+}$ oscillations. (Figure 5E). Although epinephrine triggered SCR in 45\% (5 of 11) of WT myocytes, SCR occurred in all CASQ2-deficient myocytes (11 of $11 ; P=0.03$ ). Importantly, epinephrine never triggered $\mathrm{Ca}^{2+}$ oscillations in WT myocytes (0 of 11), but epinephrine caused $\mathrm{Ca}^{2+}$ oscillations in $73 \%$ (8 of 11 ) of CASQ2-deficient myocytes $(P=0.001)$. After epinephrine washout, SR $\mathrm{Ca}^{2+}$ handling in WT cells returned to baseline, but $60 \%$ of the mutant myocytes did not recover and appeared dead (no $\mathrm{Ca}^{2+}$ transients or contraction).

Pretreatment of WT myocytes with $\mathrm{Mg}^{2+}$ resulted in decreased total $\mathrm{Ca}^{2+}$ transients (both area and peak height) and decreased sarcomere shortening, as expected for RyR2 inhibition (Supplemental Table 2). $\mathrm{Mg}^{2+}$ pretreatment of CASQ2-deficient myocytes significantly improved $\mathrm{Ca}^{2+}$ reuptake (Table 3 ). In contrast, $\mathrm{Ca}^{2+}$ release times remained prolonged in $\mathrm{Mg}^{2+}$-treated CASQ2-deficient myocytes, presumably due to $\mathrm{Mg}^{2+}$ inhibition of RyR2 channel activity. $\mathrm{Mg}^{2+}$ did not affect peak $\mathrm{Ca}^{2+}$ transients. Sarcomere shortening was reduced in $\mathrm{Mg}^{2+}$-treated CASQ2-deficient myocytes (Table 3).

Pretreatment of CASQ2-deficient myocytes with $\mathrm{Mg}^{2+}$ significantly reduced diastolic $\mathrm{Ca}^{2+}$ elevations and increased $\mathrm{Ca}^{2+}$ peak height in response to epinephrine (Table 3). Furthermore, $\mathrm{Mg}^{2+}$ treatment decreased the frequency of SCR and $\mathrm{Ca}^{2+}$ oscillations in CASQ2-deficient myocytes and significantly improved myocyte viability after epinephrine stimulation ( $85 \%$ versus $42 \% ; P=0.04$ ).

\section{Discussion}

We report on 2 mouse lines, $\mathrm{CASQ}^{\Delta \mathrm{E} 9 / \Delta \mathrm{E} 9}$ and $\mathrm{CASQ}^{307 / 307}$, that recapitulate human CPVT: normal cardiac morphology at early age, sinus bradycardia, stress-induced polymorphic ventricular arrhythmia, and

Table 2

Arrhythmias in WT and CASQ2-deficient mice at rest and with stress

\begin{tabular}{|c|c|c|c|c|c|c|c|c|c|c|}
\hline & \multicolumn{5}{|c|}{ VPBs or nonsustained VT } & \multicolumn{5}{|c|}{ Sustained VT } \\
\hline & $\begin{array}{l}\text { ControlA } \\
(n=10)\end{array}$ & $\begin{array}{c}\mathrm{M} \\
(n=10)\end{array}$ & $P$ value ${ }^{B}$ & $\begin{array}{c}\mathrm{M}+\mathrm{Mg}^{2+} \\
(n=5)\end{array}$ & $P$ valuec & $\begin{array}{l}\text { Control } \\
(n=10)\end{array}$ & $\begin{array}{c}\mathrm{M} \\
(n=10)\end{array}$ & $P$ value ${ }^{B}$ & $\begin{array}{c}\mathrm{M}+\mathrm{Mg}^{2+} \\
(n=5)\end{array}$ & $P$ valuec \\
\hline Rest & $0(0 \%)$ & $8^{B}(80 \%)$ & 0.0007 & $3(60 \%)$ & NS & $0(0 \%)$ & $1(10 \%)$ & NS & $0(0 \%)$ & NS \\
\hline Exercise & $0(0 \%)$ & $10^{B}(100 \%)$ & 0.00001 & NA & & $0(0 \%)$ & $7^{\mathrm{B}}(70 \%)$ & 0.003 & NA & \\
\hline Catecholamine & $2(20 \%)$ & $10^{B}(100 \%)$ & 0.0007 & $5(100 \%)$ & NS & $0(0 \%)$ & $10^{\mathrm{B}}(100 \%)$ & 0.00001 & $2^{C}(40 \%)$ & 0.02 \\
\hline
\end{tabular}


Table 3

$\mathrm{Ca}^{2+}$ transients and sarcomere lengths of WT and CASQ2-deficient myocytes

\begin{tabular}{|c|c|c|c|c|c|c|c|c|c|c|}
\hline & \multicolumn{5}{|c|}{ No epinephrine } & \multicolumn{5}{|c|}{ Epinephrine } \\
\hline & $\begin{array}{c}\text { WT } \\
(n=23)\end{array}$ & $\begin{array}{c}\mathrm{M} \\
(n=31)\end{array}$ & $\begin{array}{c}P \\
\text { value }^{A}\end{array}$ & $\begin{array}{c}M+M^{2+} \\
(n=13)\end{array}$ & $\begin{array}{c}P \\
\text { value }^{B}\end{array}$ & $\begin{array}{c}\text { WT } \\
(n=14)\end{array}$ & $\begin{array}{c}M \\
(n=12)\end{array}$ & $\begin{array}{c}P \\
\text { value }^{A}\end{array}$ & $\begin{array}{c}M+M^{2+} \\
(n=13)\end{array}$ & $\begin{array}{c}P \\
\text { value }^{B}\end{array}$ \\
\hline Baseline (F2 ratio) & $0.53 \pm 0.14$ & $0.58 \pm 0.11$ & NS & $0.52 \pm 0.10$ & NS & $0.49 \pm 0.09$ & $0.75 \pm 0.13^{A}$ & $<0.001$ & $0.58 \pm 0.12^{B}$ & 0.001 \\
\hline $\begin{array}{l}\text { Peak height } \\
\text { (F2 ratio) }\end{array}$ & $0.43 \pm 0.13$ & $0.44 \pm 0.14$ & NS & $0.39 \pm 0.12$ & NS & $0.56 \pm 0.17$ & $0.27 \pm 0.17^{A}$ & $<0.001$ & $0.44 \pm 0.19^{B}$ & 0.008 \\
\hline $\begin{array}{l}\text { Time to peak } \\
50 \%(\mathrm{~ms})\end{array}$ & $9 \pm 1.8$ & $11 \pm 3^{B}$ & 0.006 & $14 \pm 6$ & NS & $8 \pm 2$ & $12 \pm 7$ & NS & $10 \pm 7$ & NS \\
\hline$\tau(\mathrm{ms})$ & $122 \pm 22$ & $141 \pm 28^{A}$ & 0.01 & $120 \pm 25^{B}$ & 0.03 & $68 \pm 9$ & $66 \pm 22$ & NS & $76 \pm 22$ & NS \\
\hline Area $\left(\mathrm{mm}^{2}\right)$ & $62 \pm 21$ & $71 \pm 29$ & NS & $55 \pm 17$ & NS & $57 \pm 18^{A}$ & $27 \pm 25^{\mathrm{A}}$ & 0.002 & $39 \pm 25$ & NS \\
\hline $\begin{array}{l}\text { Rest sarcomere } \\
\text { length }(\mu \mathrm{m})\end{array}$ & $1.75 \pm 0.07$ & $1.78 \pm 0.05$ & NS & $1.74 \pm 0.05$ & NS & $1.73 \pm 0.03$ & $1.74 \pm 0.06$ & NS & $1.73 \pm 0.06$ & NS \\
\hline $\begin{array}{l}\text { Sarcomere } \\
\text { shortening }\end{array}$ & $6.31 \% \pm 1.83 \%$ & $7.4 \% \pm 3.1 \%$ & NS & $4.1 \% \pm 2.1 \% \mathrm{~B}$ & $<0.001$ & $13.3 \% \pm 1.5 \%$ & $12.1 \% \pm 3.4 \%$ & NS & $10.6 \pm 4.1$ & NS \\
\hline
\end{tabular}

WT, WT myocytes; M, mutant, myocytes from both $\mathrm{CASQ}^{307 / 307}$ and $\mathrm{CASQ}^{\Delta \mathrm{E} 9 / \mathrm{AE} 9}$ mice. ${ }^{\mathrm{A}}$ Comparison of CASQ2-deficient and WT myocytes. ${ }^{\mathrm{B} C o m p a r i s o n}$ of CASQ2-deficient myocytes treated and not treated with $\mathrm{Mg}^{2+}$.

bidirectional VT. The comparable deficiency of CASQ2 and shared phenotype of these mutant mice indicates a common pathogenetic mechanism by which this missense and null CASQ2 mutations cause disease. The compensatory responses to CASQ2 deficiency in both models included elevated RyR2 and CRT levels but unchanged calstabin levels, changes that altered $\mathrm{Ca}^{2+}$ cycling and contributed to CPVT (Figure 6). Our studies further demonstrated beneficial effects of RyR2 inhibition (e.g., $\mathrm{Mg}^{2+}$ ) in CASQ2-deficient myocytes and mice, which supports the conclusion that CPVT caused by RyR2 mutations and CPVT caused by CASQ2 mutations have a common pathophysiologic mechanism and suggests a therapeutic target.

Despite normal D307H CASQ2 mRNA levels, CASQ2 protein levels were markedly reduced in $\mathrm{CASQ}^{307 / 307}$ mice (Figure 2). We presume that $\mathrm{D} 307 \mathrm{H}$ allele encodes an unstable protein with a significantly reduced half-life. These protein data as well as the identical phenotypes in $\mathrm{CASQ}^{\mathrm{EE} 9 / \Delta \mathrm{E} 9}$ and $\mathrm{CASQ}^{307 / 307}$ mice negate the hypothesis that CASQ2 missense mutations cause disease through a dominant-negative mechanism (21). We conclude that human CASQ2 mutations cause disease by reducing CASQ2 protein levels: some CASQ2 is required in mammals to maintain myocyte $\mathrm{Ca}^{2+}$ cycling and normal cardiac electrophysiology.

An unexpected finding from these analyses is the striking compensatory increase in CRT (Figure 2C), another $\mathrm{SR} \mathrm{Ca}^{2+}$-binding protein. CRT is an important $\mathrm{Ca}^{2+}$ buffer and regulator of $\mathrm{Ca}^{2+}$ homeostasis during fetal life (26-28). CRT is highly expressed in the developing heart, but levels decrease after birth in healthy hearts (29), when CASQ2 assumes its role as the principal SR Ca ${ }^{2+}$ binding protein $(7,8)$. Finding abundant CRT RNA in adult hearts from both WT and CASQ2-deficient mice (Figure 2) strongly suggests that posttranscriptional modification accounts for decreased CRT protein after birth. Furthermore, since CRT protein levels are 10 -fold higher than normal in CASQ2-deficient hearts, we suggest that the normal increased CASQ2 expression in neonates plays a major role in CRT downregulation. Absence of this CASQ2 signal, as would occur in human CPVT gene mutations, results in persistently high CRT levels, which provide some compensatory $\mathrm{SR} \mathrm{Ca}^{2+}$-binding activity. However biophysical differences between CASQ2 and CRT also contribute to $\mathrm{Ca}^{2+}$ mishandling and promote some aspects of the CPVT phenotype. For example, the lower
$\mathrm{Ca}^{2+}$-binding capacity of CRT compared with that of CASQ2 (30, 31) may account in part for impaired $\mathrm{Ca}^{2+}$ uptake and reduced $\mathrm{SR}$ $\mathrm{Ca}^{2+}$ content of CASQ2-deficient myocytes (Figures 5 and 6).

Elevated CRT levels in CASQ2-deficient mice and humans could also explain bradycardia and sinus node dysfunction seen in CPVT patients and CPVT mice, since transgenic mice that overexpress CRT have bradyarrhythmias with SA and AV blocks $(26,32)$. We suggest that these rhythm disturbances reflect a direct change in the electrical properties of the conduction system cells rather than a degenerative process, since bradycardia present in very young CASQ2-deficient mice did not progress. Whether CRT has other direct effects on conduction system myocytes is unknown.

In addition to binding $\mathrm{Ca}^{2+}$, CASQ2 functions as a regulator of RyR2 activity $(8,16,33)$. Previous studies demonstrate that CASQ2 inhibition of the $\mathrm{Ca}^{2+}$ release channel is maximal when triadin and junctin are present and free $\mathrm{SR} \mathrm{Ca}^{2+}$ is low (15). Therefore, CASQ2 may be particularly important for reducing RyR2 channel activity during diastole (Figure 6, WT myocyte). Without CASQ2, RyR2 activity remains high during diastole, in which case persistent $\mathrm{Ca}^{2+}$ leak through RyR2 channels would contribute to the prolonged $\mathrm{Ca}^{2+}$ reuptake time observed in CASQ2-deficient myocytes (Table 3, Figure 5A, and Figure 6).

Two other differences, elevated RyR2 levels and unchanged calstabin levels, are additional causes for increased $\mathrm{Ca}^{2+}$ leak in CASQ2-deficient mice. Increased RyR2 levels may reflect a protective mechanism to maintain electromechanical coupling in CASQ2-deficient myocytes, given the reduction in total SR $\mathrm{Ca}^{2+}$ content, despite increased levels of CRT, a protein with low $\mathrm{Ca}^{2+}$ binding capacity (Figure 2, E-G). However, increased RyR2 channels are predicted to be inappropriately active, since levels of the modulatory protein calstabin are not comparably increased, and calstabin-dissociated RyR2 channels have increased probability for opening (34). Remarkably, CASQ2-deficient myocytes are well compensated under resting conditions (Figure 6). However, when adrenergic stress stimulated HR and contractility, both of which require larger and faster myocyte $\mathrm{Ca}^{2+}$ transients, these compensatory mechanisms become inadequate. For example, catecholamine-treated myocytes increased phosphorylation of RyR2 and decreased calstabin binding (34), so as to enhance RyR2 activity to 


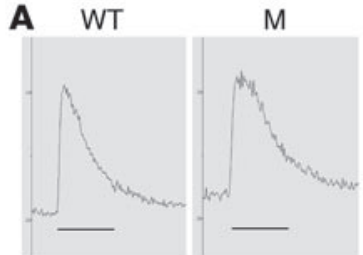

B WT

M

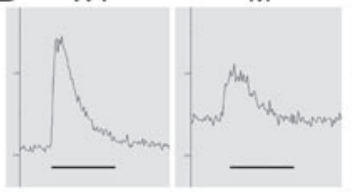

\section{D}

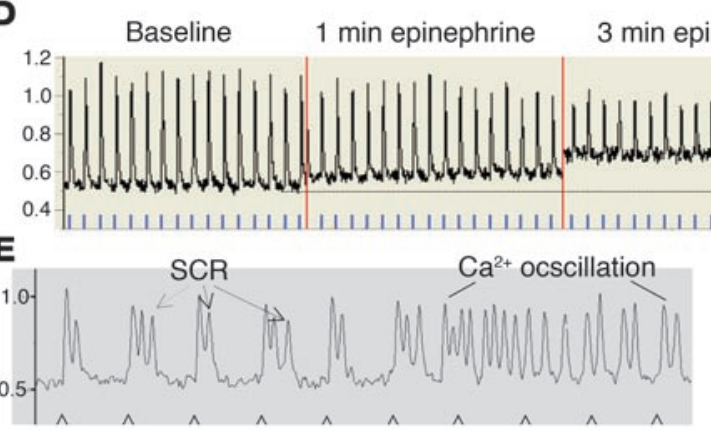

Figure 5

Functional analyses and SR $\mathrm{Ca}^{2+}$ transients of CASQ2-deficient myocytes. In $\mathrm{Ca}^{2+}$ Tyrode solution (A) and in epinephrine $5.5 \mu \mathrm{M}$ Tyrode solution (B), electrical stimulation $(60 \mathrm{~Hz})$ produced $\mathrm{Ca}^{2+}$ transients (left paired panels) and sarcomere shortening (right paired panels) of WT and CASQ2-deficient myocytes (M, CASQ ${ }^{\Delta E 9 / \triangle E 9}$ and $\mathrm{CASQ}^{307 / 307}$ ). Traces represent the average of 15 contraction-relaxation cycles from 1 representative cell of each genotype. Scale bars: 0.2 second. (C) Representative traces of caffeine-induced (10 mM) $\mathrm{Ca}^{2+}$ transients in myocytes. Scale bars: 1 second. Graphs denote pooled data from 8 WT (black) and 11 mutant (white) cells. (D) Representative traces from CASQ ${ }^{307 / 307}$ myocyte during constant epinephrine infusion for 5 minutes with electrical pacing at $1 \mathrm{~Hz}$ (blue ticks). Note elevation of diastolic $\mathrm{Ca}^{2+}$ levels (diamond), reduction of transient peak height, and development of $\mathrm{Ca}^{2+}$ oscillation after 4 minutes of epinephrine infusion (right side of the panel). (E) Representative traces from another CASQ ${ }^{307 / 307}$ myocyte in Tyrode solution during the fifth minute of epinephrine infusion show multiple events of SCR and $\mathrm{Ca}^{2+}$ oscillations. Arrows, paced electrical stimulus, $1 \mathrm{~Hz}$.

promote vigorous SR $\mathrm{Ca}^{2+}$ release. WT cells (Figure 6) responded by coordinately increasing SERCA pump activity to increase $\mathrm{Ca}^{2+}$ reuptake and coordinately increasing RyR2 when luminal $\mathrm{Ca}^{2+}$ concentrations fell (15). In contrast, CASQ2-deficient myocytes were unable to generate increased $\mathrm{Ca}^{2+}$ release due to lower SR $\mathrm{Ca}^{2+}$ stores, given the limited $\mathrm{Ca}^{2+}$-binding capacity of CRT. Although catecholamine-stimulated SERCA pump activity is enhanced in CASQ2-deficient myocytes, this mechanism for augmenting $\mathrm{Ca}^{2+}$ reuptake is offset by persistent RyR2 leak (given increased RyR2 levels, catecholamine-stimulated phosphorylation, and inappropriately low calstabin). As a consequence, epinephrine produced massive SR Ca ${ }^{2+}$ leak, total SR $\mathrm{Ca}^{2+}$ depletion, increased diastolic levels of cytosolic $\mathrm{Ca}^{2+}$, and significant decline of the peak $\mathrm{Ca}^{2+}$ transients in CASQ2-deficient myocytes (Table 3 and Figure 6).

The impact of $\mathrm{Mg}^{2+}$ on CASQ2-deficient myocytes and mice points to the critical role of the RyR2 channel in these events. $\mathrm{Mg}^{2+}$ inhibited RyR2 channels, normalized $\mathrm{Ca}^{2+}$ reuptake in CASQ2-deficient myocytes, reduced SCR, and improved viability of CASQ2deficient myocytes. Although $\mathrm{Mg}^{2+}$ may affect several ion channels, $\mathrm{Mg}^{2+}$ inhibition of RyR2 channel activity $(24,35-37)$ appeared to rargement. Whether hom human mutations promote cardiomyopathy remains uncertain, since CASQ2 mutations usually cause early lethality, and to date, no subjects with CASQ2 $2^{307 / 307}$ mutations have reached the fourth decade of life. Cardiac hypertrophy could represent tachycardiainduced cardiomyopathy (39), prolonged diastolic dysfunction due to delayed $\mathrm{Ca}^{2+}$ reuptake, or elevated diastolic $\mathrm{Ca}^{2+}$ stimulation of cardiomyopathic pathways (40).

In summary, the study of mice carrying human CASQ2 mutations provides further insights into the mechanism by which human CPVT occurs. Increased CRT and RyR2 in the SR are fundamental components of the pathology induced by CASQ2 deficiency. These tripartite changes both compensate for the absent SR $\mathrm{Ca}^{2+}$-binding protein and contribute to stress-induced arrhythmic disease. We suggest that CPVT therapeutic strategies will require targeted RyR2 inhibition and approaches to increasing SR Ca ${ }^{2+}$.

\section{Methods}

Generation of mouse models. All mouse studies were performed according to protocols approved by the Institutional Animal Care and Use Committee 
A

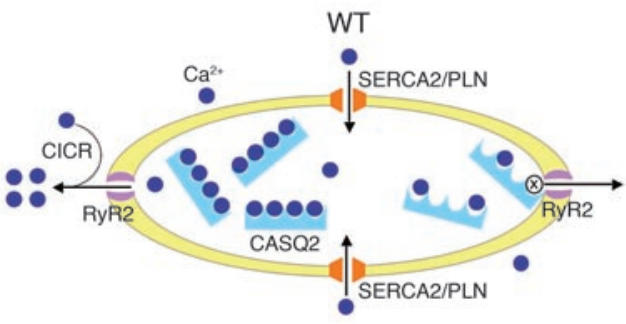

B

Resting CASQ2--

C

Stressed CASQ2 $2^{--}$
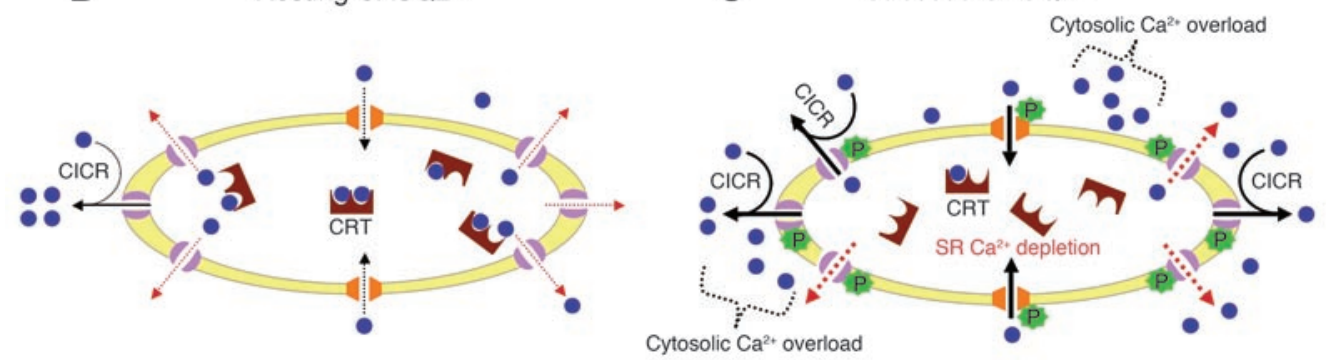

Figure 6

A model for CPVT based on abnormal SR $\mathrm{Ca}^{2+}$ homeostasis in CASQ2-deficient myocytes. (A) Under resting conditions, SR Ca' ${ }^{2+}$ (blue circles) is plentiful and buffered by CASQ2 (blue rectangles) in WT myocyte. $\mathrm{Ca}^{2+}$ influx via L-type $\mathrm{Ca}^{2+}$ channel (left side) causes Ca ${ }^{2+-i n d u c e d ~ C a}{ }^{2+}$ release (CICR) through cardiac RyR2 channels (purple). Reuptake of cytosolic $\mathrm{Ca}^{2+}$ (black arrows) occurs via the SERCA/PLN complex (orange). When SR $\mathrm{Ca}^{2+}$ concentration falls (right half), CASQ2 binds to the RyR2 channel, closing the channel (x), thus preventing Ca ${ }^{2+}$ leak (right side arrow). (B) In CASQ2-deficient myocytes, CRT (brown symbols) replaces CASQ2. Total SR Ca ${ }^{2+}$ is lower than in WT myocytes due to lower $\mathrm{Ca}^{2+-b i n d i n g ~ c a p a c i t y ~ b y ~ C R T ~(50 \% ~ o f ~ C A S Q 2) ~ a n d ~ d i a s t o l i c ~} \mathrm{Ca}^{2+}$ leak (red dashed arrows) through abundant RyR2 channels and inadequate calstabin. SERCA2-mediated $\mathrm{Ca}^{2+}$ reuptake may also be impaired (dashed black arrows) due to increased free $\mathrm{Ca}^{2+}$ gradient given lower $\mathrm{Ca}^{2+}$ binding capacity of CRT. Total SR Ca ${ }^{2+}$ transients and cytosolic $\mathrm{Ca}^{2+}$ are near normal. (C) Catecholaminergic stress applied to CASQ2-deficient myocytes phosphorylates RyR2 channels and PLN, dissociating calstabin from RyR2. Excessive RyR2 activity causes extensive diastolic Ca ${ }^{2+}$ leak, further depletes SR Ca${ }^{2+}$, reduces $\mathrm{SR} \mathrm{Ca}^{2+}$ transients, and increases cytosolic $\mathrm{Ca}^{2+}$ levels. Excess cytosolic $\mathrm{Ca}^{2+}$, effluxed via the $\mathrm{Na}^{+} / \mathrm{Ca}^{2+}$ exchanger, increases $\mathrm{Na}^{+}$entry into myocyte, which increases the probability of delayed after-polarization and cardiac arrhythmia. Toxicity of $\mathrm{Ca}^{2+}$ overload may increase myocyte death.

of Harvard Medical School. To identify a BAC encoding the mouse CASQ2 gene, a CITB CJ7-129Sv BAC library (Invitrogen) was screened using exon 9 genomic primers $\mathrm{F}-5^{\prime}$-AAAGTGGCCATTGTTTTCTGTGTCGA-3' and R-5'-GGCAAATTTCTCCTGCCTTCTAAGGA-3'. A 15-kb XmaI restriction enzyme fragment encoding intron 8, exons 9-11, and the $3^{\prime}$ region (Figure 1A) was subcloned into Bluescript vector (Stratagene) using homologous recombination technology (41). The $\mathrm{D} 307 \mathrm{H}$ mutation was introduced into exon 9 by standard PCR-based mutagenesis. A synonymous T to C substitution was introduced adjacent to the $\mathrm{D} 307 \mathrm{H}$ mutation to generate a BamHI site to facilitate convenient genotyping of modified ES cells and genetically engineered mice carrying the mutant allele. To generate the exon 9-deletion construct, a 2.2-kb KpnI/SpeI fragment containing exon 9 was excised (Figure $1 \mathrm{~A})$. Restriction fragments were ligated into the Neo-thymidine kinase vector, linearized, and electroporated into mouse ES cells for integration into the endogenous CASQ2 gene by homologous recombination (42). Targeted ES cell clones were identified by long PCR and confirmed by Southern hybridization ( $n=6$ and $n=5$ for D307H and KO constructs, respectively). Targeted ES cells were injected into C57BL/6 mouse embryos to obtain chimeric mice. D307H heterozygous mice were bred with Cre-overexpressing EIIa mice to excise the Neo between the 2 LoxP sequences of the mutant allele. Genotyping of the specific alleles of the CASQ2 gene was determined by PCR-amplified tail DNA (43). The Neo-excised allele (CASQ ${ }^{307}$ ) and the WT allele of D307H-knockin mice were screened by primers $307 \mathrm{~F}-$ 5'-AACTGAACTTAAAATTTCTATCTTGAA-3' and 307R-5'-ACTTCTCAACAGATGCCAGTATGTGC-3'. The D307H allele was amplified with primers 307FB-5'-AAAGTGGCCATTGTTTTCTGTGTCGA-3' and 307RB5'-GGCAAATTTCTCCTGCCTTCTAAGGA-3', then digested by restriction endonuclease BamHI. The exon 9-deleted allele (CASQ ${ }^{\triangle \mathrm{E} 9}$ ) and the WT allele of the $\mathrm{KO}$ mice were recognized by primers $\mathrm{F} 1-5^{\prime}$-GCCCTCGATATCAAGCTTATCGATAC-3', F2-5'-CCCTACTGTGACTCATAGTGAAGTC$3^{\prime}$, and R-5'-TTCTGTGGCCATGGCTTTCTTATG-3'.

Northern blot analysis. Northern blot analyses were performed as described $(44,45)$ using ${ }^{32} \mathrm{P}$-labeled oligonucleotide RNA probes: CASQ2, F-5'GTACGATGGGAAAGACCGAGT-3' and R-5'-CTCAAGTCAGGATTGTCAGTGTTGT-3'; CASQ1, F-5'-GCCTCGCAGAGACAATTTGAG-3' and R-5'-CATCAGGATCTGCTTCCTCTG-3'; CRT, F-5'-GCATGGAGACTCAGAATATAACATC-3' and R-5'-ATAGATATTTGCATCGGGGGAGTAT-3'; RYR2, F-5'-CTGAAGAACAGGCAGAATCTCTT-3' and R-5'-CACGGTTCGAGCTATACAACCT- $3^{\prime}$.

Protein analysis. Cytoplasmic and SR fractions were extracted from hearts of 15- to 20-week-old mice by lysis in NP40-containing buffer, and differential centrifugation was performed as described $(46,47)$. Protein concentrations were determined by the Bradford method (Bio-Rad). Western blot analyses of cell fractions were performed using standard procedures $(44,45,48)$. The following antibodies were used: rabbit polyclonal anticalsequestrin (1:2,500; Affinity BioReagents), mouse monoclonal antitriadin (1:500; Affinity BioReagents), mouse monoclonal anti-SERCA2 ATPase (1:1,000; Affinity BioReagents), rabbit polyclonal anti-calstabin (FKBP12) (1:1,000; Affinity BioReagents), mouse monoclonal anti-sorcin (1:200; Zymed Laboratories), mouse monoclonal anti-PLN (1:1,000; Millipore), rabbit polyclonal anti-phospho-PLN (Ser-16) (1:5,000; Badrilla), rabbit polyclonal anti-phospho-PLN (Thr-17) (1:5,000; Badrilla), rabbit polyclonal anti-RyR2 DeP Ser2809 (not phosphorylated at serine residue 2809; 1:5,000; Badrilla), rabbit polyclonal anti-RYR2 P Ser2809 
(phosphorylated at serine residue 2809; 1:2,000; Badrilla), rabbit polyclonal anti-CRT (1:1,000; Millipore), and mouse monoclonal anti-sarcalumenin (1:1,000; Affinity BioReagents). The ECL blotting system (Pierce Biotechnology) was used to visualize proteins.

Echocardiographic studies. Echocardiography was performed using a $15-\mathrm{MHz}$ linear array probe with a Sonos 4500 ultrasonograph (HewlettPackard), as described $(48,49)$. In brief, mice were anesthetized with i.p. injection of $2.5 \%$ tribromoethanol $(0.010 \mathrm{ml} / \mathrm{g})$, and mouse HRs were maintained at more than $550 \mathrm{bpm}$ during echocardiographic studies. The images were obtained as 2D (left parasternal long and short axes) and M-mode (left parasternal short axis) images. LV end-diastolic diameter (LVEDD), LV end-systolic diameter (LVESD), and wall thickness were obtained from M-mode tracings using measurements averaged from 3 separate cardiac cycles. LV fractional shortening (\%) was derived as follows: (LVEDD - LVESD)/LVEDD $\times 100$. A single observer, blinded to genotype, made all echocardiographic measurements. HRs were determined from ECG recordings performed during echocardiography.

Histopathology. Hearts were quickly excised, washed in PBS, fixed in $10 \%$ formaldehyde, and embedded in paraffin as described $(45,50)$. Adjacent sections were stained with $\mathrm{H} \& \mathrm{E}$ to assess myocyte disarray and hypertrophy and with Masson trichrome to assess collagen deposition resulting from fibrosis.

Electrocardiography, telemetry, and electrophysiology. Multi-lead ECG recordings, EP studies, and continuous telemetry were performed as previously described $(51,52)$. Two experienced observers blinded to mouse genotype performed all EP data analyses. Twelve-lead ECGs were obtained in anesthetized mice (pentobarbital, $0.033 \mathrm{mg} / \mathrm{kg}$ i.p.) using subcutaneous electrodes attached to each limb and chest. ECG channels between 5 and $400 \mathrm{~Hz}$ were filtered, and the analog signal was digitized with 12-bit precision at a sampling rate of $2 \mathrm{kHz}$. Mean sinus-cycle length (SCL), HR, PR interval (atrial and AV nodal conduction time), QRS duration, and QT interval were measured for each animal. A rate-corrected QT interval (QTc) was calculated using a formula appropriate for mice (53). Ambulatory electrocardiograms were obtained from subcutaneously implanted telemetric radiofrequency transmitters (DSI). After a 48-hour recovery period, resting ECGs were recorded for 1 hour during daytime, and then mice were exercised on a multilane graded treadmill (Exer-6M; Columbus Instruments). Mice initially ran at a speed of $10 \mathrm{~m} / \mathrm{min}$ and slope of 15 degrees, and speed was increased every 3 minutes for $25 \mathrm{~m} / \mathrm{min}$ until they reached exhaustion or to a maximum of 20 $\mathrm{m} / \mathrm{min}$ after 15 minutes exercise. After 1 day of recovery, mice were stressed by i.p. injection of epinephrine $(0.3 \mathrm{mg} / \mathrm{kg})$ and isoproterenol $(0.15 \mathrm{mg} / \mathrm{kg})$, administered 20 minutes apart. This pharmacologic stress was repeated following i.p. injection of magnesium $(100 \mathrm{mg} / \mathrm{kg})$. Telemetric monitoring was performed continuously during both exercise and pharmacologic stress to evaluate for atrial or ventricular arrhythmias and to assess HR response.

In vivo electrophysiology studies were performed with an octapolar $2 \mathrm{~F}$ catheter (CIBer mouse EP catheter; NuMed Inc.) inserted into the right jugular vein and advanced into the RV. Conduction system irritability was assessed during sinus rhythm and during stimulation using fixed-rate pacing and the extrastimulus technique (51). Programmed double and triple extrastimulation to the right atrium and RV were used to define arrhythmia inducibility. Complex pacing protocols involving rapid burst pacing and extrastimuli with a coupling interval of less than $50 \mathrm{~ms}$ were avoided to reduce the risk of false-positive results (54). VT was defined as a series of more than 3 consecutive repetitive ventricular ectopic beats and was denoted as sustained when lasting more than 15 seconds.
Myocyte preparation and $\mathrm{Ca}^{2+}$ measurements. Adult ventricular cardiomyocytes were isolated using a Langendorff hanging heart preparation and enzymatic digestion as previously described (55). After isolation, the cells were suspended in Tyrode buffer with gradually increasing $\mathrm{Ca}^{2+}$ concentrations $(0.06,0.24,0.6$, and $1.2 \mathrm{mM}, \mathrm{pH} 7.4$ at room temperature) and were loaded with $1 \mu \mathrm{M}$ fura-2/AM Ca ${ }^{2+}$ indicator (Invitrogen) as previously described (56). Cardiomyocytes were perfused with $1.2 \mathrm{mM} / 1 \mathrm{Ca}^{2+}$ Tyrode solution containing $0.5 \mathrm{mM} / 1 \mathrm{Mg}^{2+}$ at $37^{\circ} \mathrm{C}$ and electrically paced at 60 $\mathrm{bpm}$ via platinum wires. Sarcomere shortening/relengthening and fura-2 fluorescence ratios (which reflect the intracellular $\mathrm{Ca}^{2+}$ transients) were simultaneously recorded and determined from discrete striation positions on myocytes, using a dual-excitation fluorescence imaging/contractility recording system (IonWizard SarcLen detection and PMT Acquisition fluorescence system; IonOptix Corp.). Sarcomere length and $\mathrm{Ca}^{2+}$ recordings were performed in Tyrode buffer and in Tyrode buffer containing $5.5 \mu \mathrm{M}$. Some recordings were performed in a high $\mathrm{Mg}^{2+}(3 \mathrm{mM} / \mathrm{l})$ Tyrode buffer. SR $\mathrm{Ca}^{2+}$ load was assessed via a rapid puff of caffeine $(10 \mathrm{mM})$ to fura-2-loaded myocytes without electric stimulation. $\mathrm{Ca}^{2+}$ transients due to trans-sarcolemmal $\mathrm{Ca}^{2+}$ movement were assessed by electrical pacing during constant caffeine perfusion. Percentage of sarcomere shortening was expressed as the difference between resting and twitch sarcomere length normalized to resting sarcomere length. $\mathrm{Ca}^{2+}$ transient analysis, including baseline levels, peak $\mathrm{Ca}^{2+}$ change (peak height), departure velocity, time constant for $\mathrm{Ca}^{2+}$ transient decay $(\tau)$, and the area under the $\mathrm{Ca}^{2+}$ transient curve were calculated using IonOptix transient analysis software (version 5.0; IonWizard).

All myocytes studied were rod shaped with a clear striation pattern and quiescent in the absence of electrical stimulation, with a resting sarcomere length of at least $1.6 \mu \mathrm{m}$.

Statistics. Differences between groups of WT and mutant mice or cells were determined using the unpaired Student's $t$ test for continuous variables and the Fisher exact test for categorized variables. Data are expressed as mean $\pm \mathrm{SD}$. $P$ values of less than 0.05 were considered statistically significant.

\section{Acknowledgments}

We thank Mikhail Bourgoun for echocardiographic analyses. This work was supported by a grant from the Howard Hughes Medical Institute (to C.E. Seidman), grants from the NIH (to J.G. Seidman and C.E. Seidman), an Israel Scientific Foundation grant (to M. Arad and M. Eldar), and an American Physician Fellowship in Israel grant (to R. Alcalai).

Received for publication November 28, 2006, and accepted in revised form March 20, 2007.

Address correspondence to: J.G. Seidman, Department of Genetics, NRB Room 256, Harvard Medical School, 77 Avenue Louis Pasteur, Boston, Massachusetts 02115, USA. Phone: (617) 432-7871; Fax: (617) 432-7832; E-mail: seidman@genetics.med.harvard.edu.

Lei Song, Ronny Alcalai, and Michael Arad contributed equally to this work.

Christine E. Seidman and J.G. Seidman contributed equally to this work.
1. Leenhardt, A., et al. 1995. Catecholaminergic poly-
morphic ventricular tachycardia in children. A 7-year
follow-up of 21 patients. Circulation. 91:1512-1519.
2. Priori, S.G., et al. 2002. Clinical and molecular
characterization of patients with catecholaminer- gic polymorphic ventricular tachycardia. Circulation. 106:69-74.

3. Lahat, H., et al. 2001. Autosomal recessive catecholamine- or exercise-induced polymorphic ventricular tachycardia: clinical features and assignment of the disease gene to chromosome 1p13-21. Circulation 103:2822-2827.

4. Postma, A.V., et al. 2002. Absence of calsequestrin 2 causes severe forms of catecholaminergic polymorphic ventricular tachycardia. Circ. Res. 91:e21-e26. 
5. Molkentin, J.D. 2006. Dichotomy of $\mathrm{Ca}^{2+}$ in the heart: contraction versus intracellular signaling. J. Clin. Invest. 116:623-626. doi:10.1172/JCI27824.

6. Saks, V., et al. 2006. Cardiac system bioenergetics: metabolic basis of the Frank-Starling law. J. Physiol. 571:253-273

7. Beard, N.A., Laver, D.R., and Dulhunty, A.F. 2004. Calsequestrin and the calcium release channel of skeletal and cardiac muscle. Prog. Biophys. Mol. Biol. 85:33-69.

8. Yano, K., and Zarain-Herzberg, A. 1994. Sarcoplasmic reticulum calsequestrins: structural and functional properties. Mol. Cell. Biochem. 135:61-70.

9. Treves, S., Vilsen, B., Chiozzi, P., Andersen, J.P., and Zorzato, F. 1992. Molecular cloning, functional expression and tissue distribution of the cDNA encoding frog skeletal muscle calsequestrin. Biochem. J. 283:767-772.

10. Slupsky, J.R., Ohnishi, M., Carpenter, M.R., and Reithmeier, R.A. 1987. Characterization of cardiac calsequestrin. Biochemistry. 26:6539-6544.

11. Cozens, B., and Reithmeier, R.A. 1984. Size and shape of rabbit skeletal muscle calsequestrin. J. Biol. Chem. 259:6248-6252.

12. Scott, B.T., Simmerman, H.K., Collins, J.H., Nadal-Ginard, B., and Jones, L.R. 1988. Complete amino acid sequence of canine cardiac calsequestrin deduced by cDNA cloning. J. Biol. Chem. 263:8958-8964.

13. Campbell, K.P., MacLennan, D.H., Jorgensen, A.O., and Mintzer, M.C. 1983. Purification and characterization of calsequestrin from canine cardiac sarcoplasmic reticulum and identification of the 53,000 dalton glycoprotein. J. Biol. Chem. 258:1197-1204.

14. Szegedi, C., Sarkozi, S., Herzog, A., Jona, I., and Varsanyi, M. 1999. Calsequestrin: more than 'only' a luminal $\mathrm{Ca} 2+$ buffer inside the sarcoplasmic reticulum. Biochem. J. 337:19-22.

15. Gyorke, I., Hester, N., Jones, L.R., and Gyorke, S. 2004. The role of calsequestrin, triadin, and junctin in conferring cardiac ryanodine receptor responsiveness to luminal calcium. Biophys. J. 86:2121-2128.

16. Zhang, L., Kelley, J., Schmeisser, G., Kobayashi, Y.M., and Jones, L.R. 1997. Complex formation between junctin, triadin, calsequestrin, and the ryanodine receptor. Proteins of the cardiac junctional sarcoplasmic reticulum membrane. J. Biol. Chem. 272:23389-23397.

17. Lahat, H., et al. 2001. A missense mutation in a highly conserved region of CASQ2 is associated with autosomal recessive catecholamine-induced polymorphic ventricular tachycardia in Bedouin families from Israel. Am. J. Hum. Genet. 69:1378-1384.

18. di Barletta, M.R., et al. 2006. Clinical phenotype and functional characterization of CASQ2 mutations associated with catecholaminergic polymorphic ventricular tachycardia. Circulation. 114:1012-1019.

19. Terentyev, D., et al. 2006. Abnormal interactions of calsequestrin with the ryanodine receptor calcium release channel complex linked to exercise-induced sudden cardiac death. Circ. Res. 98:1151-1158.

20. Knollmann, B.C., et al. 2006. Casq2 deletion causes sarcoplasmic reticulum volume increase, premature $\mathrm{Ca}^{2+}$ release, and catecholaminergic poly- morphic ventricular tachycardia. J. Clin. Invest. 116:2510-2520. doi:10.1172/JCI29128.

21. Viatchenko-Karpinski, S., et al. 2004. Abnormal calcium signaling and sudden cardiac death associated with mutation of calsequestrin. Circ. Res. 94:471-477.

22. Houle, T.D., Ram, M.L., and Cala, S.E. 2004. Calsequestrin mutant D307h exhibits depressed binding to its protein targets and a depressed response to calcium. Cardiovasc. Res. 64:227-233.

23. Cerrone, M., et al. 2005. Bidirectional ventricular tachycardia and fibrillation elicited in a knock-in mouse model carrier of a mutation in the cardiac ryanodine receptor. Circ. Res. 96:e77-e82.

24. Laver, D.R., Baynes, T.M., and Dulhunty, A.F. 1997. Magnesium inhibition of ryanodine-receptor calcium channels: evidence for two independent mechanisms. J. Membr. Biol. 156:213-229.

25. Tzivoni, D., et al. 1988. Treatment of torsade de pointes with magnesium sulfate. Circulation. 77:392-397.

26. Michalak, M., Guo, L., Robertson, M., Lozak, M., and Opas, M. 2004. Calreticulin in the heart. Mol. Cell. Biochem. 263:137-142.

27. Michalak, M., Corbett, E.F., Mesaeli, N., Nakamura, K., and Opas, M. 1999. Calreticulin: one protein, one gene, many functions. Biochem. J. 344:281-292.

28. Mesaeli, N., et al. 1999. Calreticulin is essential for cardiac development. J. Cell Biol. 144:857-868.

29. Lynch, J.M., Chilibeck, K., Qui, Y., and Michalak, M. 2006. Assembling pieces of the cardiac puzzle; calreticulin and calcium-dependent pathways in cardiac development, health, and disease. Trends Cardiovasc. Med. 16:65-69.

30. Meldolesi, J., and Pozzan, T. 1998. The endoplasmic reticulum $\mathrm{Ca} 2+$ store: a view from the lumen. Trends Biochem. Sci. 23:10-14.

31. Krause, K.H., and Michalak, M. 1997. Calreticulin. Cell. 88:439-443.

32. Nakamura, K., et al. 2001. Complete heart block and sudden death in mice overexpressing calreticulin. J. Clin. Invest. 107:1245-1253.

33. Beard, N.A., et al. 2005. Regulation of ryanodine receptors by calsequestrin: effect of high luminal $\mathrm{Ca} 2+$ and phosphorylation. Biophys. J. 88:3444-3454.

34. Lehnart, S.E., et al. 2006. Stabilization of cardiac ryanodine receptor prevents intracellular calcium leak and arrhythmias. Proc. Natl. Acad. Sci. U. S. A. 103:7906-7910.

35. Lamb, G.D., and Stephenson, D.G. 1991. Effect of $\mathrm{Mg} 2+$ on the control of $\mathrm{Ca} 2+$ release in skeletal muscle fibres of the toad. J. Physiol. 434:507-528.

36. Meissner, G. 1994. Ryanodine receptor/Ca2+ release channels and their regulation by endogenous effectors. Annu. Rev. Physiol. 56:485-508.

37. Laver, D.R. 2005. Coupled calcium release channels and their regulation by luminal and cytosolic ions. Eur. Biophys. J. 34:359-368.

38. Iyer, V., Hajjar, R.J., and Armoundas, A.A. 2007. Mechanisms of abnormal calcium homeostasis in mutations responsible for catecholaminergic polymorphic ventricular tachycardia. Circ. Res. 100:e22-e31.

39. Shinbane, J.S., et al. 1997. Tachycardia-induced cardiomyopathy: a review of animal models and clinical studies. J. Am. Coll. Cardiol. 29:709-715.

40. Wilkins, B.J., and Molkentin, J.D. 2004. Calciumcalcineurin signaling in the regulation of cardiac hypertrophy. Biochem. Biophys. Res. Commun. 322:1178-1191.

41. Liu, P., Jenkins, N.A., and Copeland, N.G. 2003. A highly efficient recombineering-based method for generating conditional knockout mutations. Genome Res. 13:476-484.

42. Bruneau, B.G., et al. 2001. A murine model of HoltOram syndrome defines roles of the T-box transcription factor Tbx5 in cardiogenesis and disease. Cell. 106:709-721.

43. Truett, G.E., et al. 2000. Preparation of PCR-quality mouse genomic DNA with hot sodium hydroxide and Tris (HotSHOT). Biotechniques. 29:52, 54.

44. Ausubel, F., et al. 2006. Current protocols in molecular biology. John Wiley and Sons, Inc. New York, New York, USA. 4900 pp.

45. Semsarian, C., et al. 2002. The L-type calcium channel inhibitor diltiazem prevents cardiomyopathy in a mouse model. J. Clin. Invest. 109:1013-1020. doi:10.1172/JCI200214677.

46. Eletr, S., and Inesi, G. 1972. Phospholipid orientation in sarcoplasmic membranes: spin-label ESR and proton MNR studies. Biochim. Biophys. Acta. 282:174-179.

47. Heilmann, C., Brdiczka, D., Nickel, E., and Pette, D. 1977. ATPase activities, Ca2 + transport and phosphoprotein formation in sarcoplasmic reticulum subfractions of fast and slow rabbit muscles. Eur. J. Biochem. 81:211-222.

48. McConnell, B.K., et al. 2001. Comparison of two murine models of familial hypertrophic cardiomyopathy. Circ. Res. 88:383-389.

49. Fatkin, D., et al. 2000. An abnormal Ca ${ }^{2+}$ response in mutant sarcomere protein-mediated familial hypertrophic cardiomyopathy. J. Clin. Invest. 106:1351-1359.

50. Arad, M., et al. 2003. Transgenic mice overexpressing mutant PRKAG2 define the cause of WolffParkinson-White syndrome in glycogen storage cardiomyopathy. Circulation. 107:2850-2856.

51. Berul, C.I., Aronovitz, M.J., Wang, P.J., and Mendelsohn, M.E. 1996. In vivo cardiac electrophysiology studies in the mouse. Circulation. 94:2641-2648.

52. Gehrmann, J., and Berul, C.I. 2000. Cardiac electrophysiology in genetically engineered mice. J. Cardiovasc. Electrophysiol. 11:354-368.

53. Mitchell, G.F., Jeron, A., and Koren, G. 1998. Measurement of heart rate and Q-T interval in the conscious mouse. Am. J. Physiol. 274:H747-H751.

54. Maguire, C.T., et al. 2003. Implications of ventricular arrhythmia vulnerability during murine electrophysiology studies. Physiol. Genomics. 15:84-91.

55. Lim, C.C., Apstein, C.S., Colucci, W.S., and Liao, R. 2000. Impaired cell shortening and relengthening with increased pacing frequency are intrinsic to the senescent mouse cardiomyocyte. J. Mol. Cell. Cardiol. 32:2075-2082.

56. Nagata, K., et al. 1998. Early changes in excitationcontraction coupling: transition from compensated hypertrophy to failure in Dahl salt-sensitive rat myocytes. Cardiovasc. Res. 37:467-477. 